\title{
Side-Chain Liquid-Crystalline Polymers Containing the Siloxane Spacer V. Syntheses and Thermal Properties of Copolymethacrylates with Different Spacer Structures
}

\author{
Eiichi AkiYama, Yuriko Takamura, and Yu Nagase* \\ Sagami Chemical Research Center, \\ Nishi-Ohnuma, Sagamihara, Kanagawa 229, Japan
}

(Received May 19, 1994)

\begin{abstract}
Copolymerizations of the methacrylate-type monomers whose spacer consisted of only alkylene unit with the comonomers containing a disiloxane unit in the spacer component were carried out by radical polymerization. The effects of copolymer composition and structure of mesogen on the mesomorphic properties of the obtained copolymers were investigated, using DSC, optical polarizing microscope and X-ray diffractometry. $T_{\mathrm{g}}$ and $T_{\mathrm{i}}$ of the copolymers decreased with increase in comonomer component reflecting the flexibility of the siloxane linkage. The introduction of the comonomer containing a siloxane spacer and a laterally attached mesogen was effective to lower the temperature range of the mesophase. The copolymers, of which the comonomer content was about $50 \mathrm{~mol} \%$, exhibited an enantiotropic nematic phase, whereas the parent homopolymers exhibited a smectic phase. Consequently, the mesophase and temperature range of liquid crystalline state could be controlled by the introduction of a comonomer unit containing a siloxane spacer.
\end{abstract}

KEY WORDS Siloxane Spacer / Polymethacrylate / Copolymer / Liquid Crystal / Transition Temperature / Mesophase /

To obtain the mesophase of side-chain liquid-crystalline polymer (LCP), the introduction of flexible spacer groups between the polymer main chain and mesogenic side chain is necessary to decouple the motions of the backbone components from those of the anisotropically oriented mesogenic group. ${ }^{1}$ Recently, we reported the synthesis and thermal properties of side-chain LCPs containing a siloxane bond in the spacer component. $^{2-5}$ The introduction of a flexible siloxane unit in the spacer lowered the temperature range of the mesophase of the polymers, in comparison with polymers having an alkylene spacer with the same backbone component and mesogens. ${ }^{3}$ This would be due to the low rotational energy barrier of the siloxane linkage. However, only when triplecore mesogens were introduced, the stable smectic mesophase was observed with a wide range of phase stability, while no mesophase was observed for the linear double-core and laterally attached mesogens. This is in good agreement with the thermal properties of similar LCPs reported by Engel et al. ${ }^{6}$ They suggested that the mesophase was only found with long alkyl chains in the spacer or triple-core mesogens, because the bulky siloxane group disturbs the liquid-crystalline order. On the contrary, a study has been done by Kawakami et al., ${ }^{7}$ which includes the side-chain liquid crystalline polydiene containing a disiloxane unit in the spacer component with a compact biphenylene-type mesogenic group.

The present article describes the thermal properties of copolymers, which consist of two monomer units having an alkylene spacer and 
a siloxane spacer. For these copolymers, it is expected that the monomer units whose parent homopolymers show no mesophase may disturb the liquid-crystalline order, and copolymers exhibit a lower ordered mesophase, that is, a nematic phase. The effects of copolymer composition on the thermal property are discussed. Copolymerization of the mesogenic monomers was frequently employed to manipulate the phase transitions or kinds of mesophases of side-chain LCPs. $^{8}$ In our previous paper, ${ }^{4}$ the copolymers containing the disiloxane unit in the spacer component with double-core and triple-core mesogens were investigated, which exhibited a nematic phase.

\section{EXPERIMENTAL}

\section{Materials}

4'-Butoxybiphenyl-4-ol and 4'-octoxy biphenyl-4-ol were furnished from Chisso Corporation. The condensation catalyst, polyphosphoric ester (PPE), were prepared according to the literature. ${ }^{9}$ Tetrahydrofuran (THF) used as the solvent was distilled twice (over $\mathrm{CaH}_{2}$ and sodium), and chloroform was also distilled over $\mathrm{CaH}_{2}$ to remove traces of water. 2,2'-Azobisisobutyronitrile (AIBN) was purchased from Tokyo Kasei Co. Ltd., and used without further purification. All other chemicals were of reagent grade and obtained

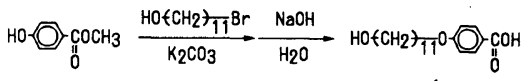

$$
\begin{aligned}
& \mathcal{1}
\end{aligned}
$$

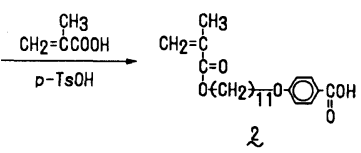

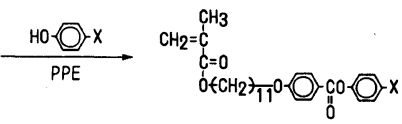

$$
\begin{aligned}
& X=-\mathrm{CN}(3 a),-\mathrm{OC}_{4} \mathrm{H}_{9}(3 \mathrm{~b}) \text {. } \\
& \text { (O) } \mathrm{OC}_{4} \mathrm{Hg}_{9}(3 \mathrm{c}), \quad \text { O) } \mathrm{OC}_{8} \mathrm{H}_{17}(\text { (3d). }
\end{aligned}
$$

Scheme 1. Preparations of monomers with an alkylene spacer. commercially.

The monomers with an alkylene spacer and those with a siloxane spacer were prepared according to Schemes $1-3$, respectively. The

$$
\begin{aligned}
& \mathrm{HO}-\underset{\mathrm{O}}{\mathrm{COCH}} \underset{\mathrm{K}_{2} \mathrm{CO}_{3}}{\stackrel{\mathrm{CH}_{2}=\mathrm{CHCH}_{2} \mathrm{Br}}{\longrightarrow}} \frac{\mathrm{NaOH}}{\mathrm{H}_{2} \mathrm{O}} \mathrm{CH}_{2}=\mathrm{CHCH}_{2} \mathrm{O} \underset{\mathrm{II}}{\mathrm{COH}} \\
& \stackrel{4}{\sim}
\end{aligned}
$$

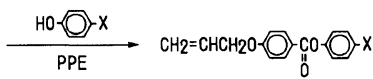

$$
\begin{aligned}
& X=-\mathrm{CN}(\underset{\sim}{(5 a}),-\mathrm{OC}_{4} \mathrm{Hg}(\underset{\sim}{\sim} \mathrm{b}) \text {. } \\
& \text { (O) } \mathrm{OC}_{4} \mathrm{H}_{9}(5 \mathrm{c}), \quad \text { (O) } \mathrm{OC}_{8} \mathrm{H}_{17}(5 \mathrm{~d}) \text {. }
\end{aligned}
$$

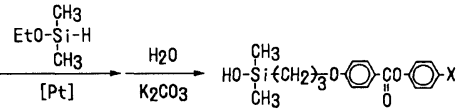

$$
\begin{aligned}
& X=-C N(\underset{\sim}{a}),-\mathrm{OC}_{4} \mathrm{H}_{9}(\underset{\mathrm{\sigma}}{\mathrm{b}}) \text {, } \\
& \text { (O) } \mathrm{OC}_{4} \mathrm{H}_{9}(\underset{\mathrm{c}}{\mathrm{c}}) \text {. (O) } \mathrm{OC}_{8 \mathrm{H}_{17}}(\underset{\mathrm{c}}{\mathrm{d}}) \text {. }
\end{aligned}
$$

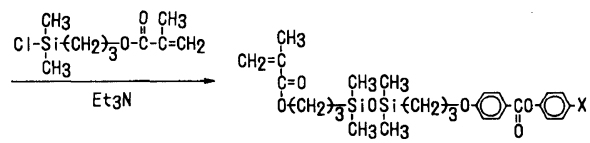

$$
\begin{aligned}
& X=-C N(\underset{\sim}{7 a}),-\mathrm{OC}_{4} \mathrm{Hg}(\underset{\sim}{\mathrm{r}} \mathrm{b}) . \\
& \text { (O) } \mathrm{OC}_{4} \mathrm{Hg} \text { (7c). (O) } \mathrm{OC}_{8} \mathrm{H}_{17} \text { (7d). }
\end{aligned}
$$

Scheme 2. Preparations of monomers with a siloxane spacer.

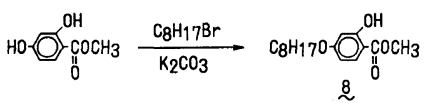

$$
\begin{aligned}
& \underset{\mathrm{K}_{2} \mathrm{CO}_{3}}{\stackrel{\mathrm{CH}_{2}=\mathrm{CHCH}_{2} \mathrm{CH} 2 \mathrm{Br}}{\longrightarrow}} \frac{\mathrm{NaOH}}{\mathrm{H}_{2} \mathrm{O}} \mathrm{C}_{8} \mathrm{H}_{170}-\underbrace{\mathrm{O}_{\mathrm{NO}}^{\mathrm{O}}}_{2} \mathrm{CH}_{2} \mathrm{CH}_{2} \mathrm{CH}=\mathrm{CH}_{2}
\end{aligned}
$$

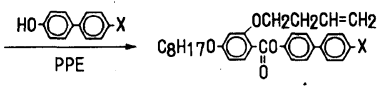

$$
\begin{aligned}
& X=-C N(\underset{\sim}{\sim} a),-O C_{4} H_{9}(10 b) \text {. }
\end{aligned}
$$

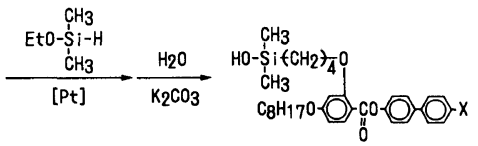

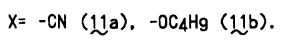

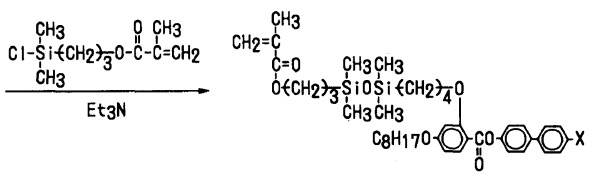

$$
\begin{aligned}
& X=-C N(12 a),-O_{4} \mathrm{Hg}_{9}(12 b) \text {. }
\end{aligned}
$$

Scheme 3. Preparations of monomers with a siloxane spacer. 
synthetic procedures of the monomers with a siloxane spacer, 7a-7d, 12a, and $\mathbf{1 2 b}$, have been already described in our previous report. ${ }^{3}$ Details of the preparations of the monomers, 3a-3d, including those of their intermediates are described below.

\section{4-(11-Hydroxyundecyloxy)benzoic Acid (1)}

Methyl 4-hydroxybenzoate $(11.0 \mathrm{~g}, 72.5$ mmol), 11-bromoundecan-1-ol (20.0 g, 79.6 $\mathrm{mmol})$ and $\mathrm{K}_{2} \mathrm{CO}_{3}(10.0 \mathrm{~g}, 72.4 \mathrm{mmol})$ were dissolved in $100 \mathrm{ml}$ of 2-butanone, and the mixture was refluxed for $48 \mathrm{~h}$. The solution was cooled to room temperature to precipitate a white solid. The product was filtered and washed with hexane and water to afford $20.2 \mathrm{~g}$ of methyl 4-(11-hydroxyundecyloxy)benzoate as a white solid. Yield, $86.7 \%$.

The obtained methyl 4-(11-hydroxyundecyloxy)benzoate $(20.2 \mathrm{~g}, 65.6 \mathrm{mmol})$ was dissolved in a mixture of $50 \mathrm{ml}$ of methanol and $50 \mathrm{ml}$ of acetone. To this solution, one containing $\mathrm{NaOH}(14.0 \mathrm{~g}, 350 \mathrm{mmol})$ in $100 \mathrm{ml}$ of water was added, and the mixture was refluxed for $2 \mathrm{~h}$. After the solvent was distilled off, the residue was dissolved in water, and hydrochloric acid was added until the solution became acidic, whereupon a white precipitate formed. The product was filtered and washed with water to afford $19.1 \mathrm{~g}$ of $\mathbf{1}$ as a white solid. Yield, 98.5\%.

IR $\left(\mathrm{KBr}, \mathrm{cm}^{-1}\right): 3430(-\mathrm{OH}), 2910,2850$, 2670, 2550, $1670(\mathrm{C}=\mathrm{O}), 1602,1435,1302$, 1248, 1162, 1140, 840, 762, 640 .

${ }^{1} \mathrm{H}$ NMR $\delta\left(\mathrm{CDCl}_{3}, \mathrm{ppm}\right): 1.20-2.00(\mathrm{~m}$, $18 \mathrm{H}), 3.62(\mathrm{t}, 2 \mathrm{H}), 4.00(\mathrm{t}, 2 \mathrm{H}), 6.90(\mathrm{~d}, 2 \mathrm{H}$, $J=9.0 \mathrm{~Hz}), 8.01(\mathrm{~d}, 2 \mathrm{H}, J=9.0 \mathrm{~Hz})$.

\section{4-(11-Methacryloxyundecyloxy)benzoic Acid}

(2)

$1(15.0 \mathrm{~g}, 48.6 \mathrm{mmol})$, methacrylic acid $(60.0$ $\mathrm{g}, 697 \mathrm{mmol})$ and tosylic acid $(2.00 \mathrm{~g}, 11.6$ $\mathrm{mmol}$ ) were dissolved in $200 \mathrm{ml}$ of chloroform. To this solution, $3.0 \mathrm{~g}$ of hydroquinone were added as a radical scavenger, and the mixture was refluxed for $13 \mathrm{~h}$ with an azeotrope trap to remove produced water. The reaction mixture was poured into $800 \mathrm{ml}$ of ice-water, where a white precipitate formed. After the product was filtered and washed with a aqueous sodium carbonate solution and water, it was purified by recrystallization from acetone to afford $14.5 \mathrm{~g}$ of 2 as a white solid. Yield, $78.9 \%$.

IR $\left(\mathrm{KBr}, \mathrm{cm}^{-1}\right): 2915,2848,2660,2550$, $1700,1680(\mathrm{C}=\mathrm{O}), 1630,1600,1425,1250$, $1168,768,640$.

${ }^{1} \mathrm{H}$ NMR $\delta\left(\mathrm{CDCl}_{3}, \mathrm{ppm}\right): 1.00-1.90(\mathrm{~m}$, $18 \mathrm{H}), 4.02(\mathrm{t}, 2 \mathrm{H}, J=6.2 \mathrm{~Hz}), 4.14(\mathrm{t}, 2 \mathrm{H}$, $J=6.2 \mathrm{~Hz}), 5.53(\mathrm{~s}, 1 \mathrm{H}), 6.09(\mathrm{~s}, 1 \mathrm{H}), 6.92(\mathrm{~d}$, $2 \mathrm{H}, J=9.0 \mathrm{~Hz}), 8.03(\mathrm{~d}, 2 \mathrm{H}, J=9.0 \mathrm{~Hz})$.

\section{Monomers with an Alkylene Spacer (3a-3d)}

Monomers 3a-3d were prepared from $\mathbf{2}$ by condensation with the corresponding phenol compounds. A typical procedure is as follows; $2(2.53 \mathrm{~g}, 6.72 \mathrm{mmol})$, 4-cyanophenol $(0.80 \mathrm{~g}$, $6.72 \mathrm{mmol})$ and excess PPE $(20 \mathrm{~g})$ were dissolved in $20 \mathrm{ml}$ of chloroform under an argon atmosphere, and the mixture was stirred for $24 \mathrm{~h}$ at room temperature. $200 \mathrm{ml}$ of water were added and the mixture was extracted with $\mathrm{CH}_{2} \mathrm{Cl}_{2}$. After the solvent was distilled off, the product was purified by column chromatography on silica gel with $\mathrm{CH}_{2} \mathrm{Cl}_{2}-$ hexane $(1: 2$ by volume) as the eluent to afford $2.40 \mathrm{~g}$ of $\mathbf{3 a}$ as a white solid. Yield, $74.8 \%$.

IR $\left(\mathrm{KBr}, \mathrm{cm}^{-1}\right)$ : 2910, 2850, $2225(\mathrm{CN})$, 1738, $1710(\mathrm{C}=\mathrm{O}), 1632,1600,1510,1252$, 1212, 1162, 1065, 755, 548.

${ }^{1} \mathrm{H}$ NMR $\delta\left(\mathrm{CDCl}_{3}, \mathrm{ppm}\right): 1.20-1.95(\mathrm{~m}$, $18 \mathrm{H}), 2.90(\mathrm{~s}, 3 \mathrm{H}), 4.03(\mathrm{t}, 2 \mathrm{H}), 4.12(\mathrm{t}, 2 \mathrm{H})$, $5.52(\mathrm{~s}, 1 \mathrm{H}), 6.07(\mathrm{~s}, 1 \mathrm{H}), 6.96(\mathrm{~d}, 2 \mathrm{H}$, $J=9.0 \mathrm{~Hz}), 7.33(\mathrm{~d}, 2 \mathrm{H}, J=8.8 \mathrm{~Hz}), 7.72(\mathrm{~d}$, $2 \mathrm{H}, J=9.0 \mathrm{~Hz}), 8.10(\mathrm{~d}, 2 \mathrm{H}, J=8.8 \mathrm{~Hz})$.

In the above reaction, 4-butoxyphenol, 4'butoxybiphneyl-4-ol, and 4'-octoxybiphenyl-4ol were used instead of 4-cyanophenol, to afford $\mathbf{3 b}, \mathbf{3 c}$, and $\mathbf{3 d}$, respectively.

\section{Copolymerization}

Each pair of monomers $(3 \mathbf{a} / 7 \mathbf{a}, 3 \mathbf{3 b} / \mathbf{7 b}$, $3 \mathbf{a} / 12 \mathbf{a}, 3 \mathbf{b} / 12 \mathbf{b}, 3 \mathbf{c} / 7 \mathbf{c}$, and $3 d / 7 d)$ and $A I B N$ 
Table I. Results of preparations and thermal transitions of copolymers

\begin{tabular}{|c|c|c|c|c|c|c|c|c|}
\hline \multirow{2}{*}{$\begin{array}{l}\text { Sample } \\
\text { code }\end{array}$} & \multirow{2}{*}{$\begin{array}{c}\text { Monomer } \\
\left(\mathrm{M}_{1}\right)\end{array}$} & \multirow{2}{*}{$\begin{array}{c}1 \text { Monomer } 2 \\
\left(\mathrm{M}_{2}\right)\end{array}$} & \multirow{2}{*}{$\frac{\mathrm{M}_{1} / \mathbf{M}_{2}^{\mathrm{a}}}{\text { mole ratio }}$} & \multirow{2}{*}{$\frac{x / y^{\mathrm{b}}}{\text { mole ratio }}$} & \multirow{2}{*}{$\begin{array}{c}\bar{M}_{n}^{\mathrm{c}} \\
\times 10^{-4}\end{array}$} & \multirow{2}{*}{$\begin{array}{c}\bar{M}_{w}^{\mathrm{c}} \\
\times 10^{-4}\end{array}$} & \multirow{2}{*}{$\frac{\begin{array}{c}\text { Transition } \\
\text { temperature }\end{array}}{{ }^{\mathrm{o}} \mathrm{C}}$} & \multirow{2}{*}{$\frac{\Delta H \text { at } T_{i}^{\mathrm{e}}}{\mathrm{mJ} \mathrm{mg}^{-1}}$} \\
\hline & & & & & & & & \\
\hline CP-1 & $\mathbf{3 a}$ & $7 \mathbf{a}$ & $75 / 25$ & $78 / 22$ & 1.97 & 2.86 & g $36 \mathrm{~S} 105 \mathrm{I}$ & 5.7 \\
\hline CP-2 & $\mathbf{3 a}$ & $7 \mathbf{a}$ & $50 / 50$ & $49 / 51$ & 2.15 & 2.88 & g $14 \mathrm{~N} 72 \mathrm{I}$ & 3.4 \\
\hline CP-3 & $\mathbf{3 b}$ & $7 \mathbf{b}$ & $75 / 25$ & $72 / 28$ & 3.99 & 6.48 & g $33 \mathrm{~S} 101 \mathrm{I}$ & 10.2 \\
\hline CP-4 & 3b & $7 \mathbf{b}$ & $50 / 50$ & $47 / 53$ & 3.57 & 5.45 & g $8 \mathrm{~N} 65 \mathrm{I}$ & 6.8 \\
\hline CP-5 & $3 \mathbf{a}$ & $12 a$ & $75 / 25$ & $81 / 19$ & 1.98 & 2.88 & g $12 \mathrm{~S} 71 \mathrm{I}$ & 1.2 \\
\hline CP-6 & 3a & $12 a$ & $50 / 50$ & $55 / 45$ & 1.36 & 2.17 & g $14 \mathrm{~N} \quad 32 \mathrm{I}$ & 0.7 \\
\hline CP-7 & $\mathbf{3 b}$ & $12 b$ & $75 / 25$ & $75 / 25$ & 6.57 & 9.73 & g $19 \mathrm{~S} 90 \mathrm{I}$ & 4.8 \\
\hline CP-8 & $\mathbf{3 b}$ & $12 b$ & $50 / 50$ & $62 / 38$ & 2.70 & 3.91 & $\mathrm{~g} 12 \mathrm{~N} 51 \mathrm{I}$ & 1.0 \\
\hline CP-9 & $3 c$ & $7 c$ & $50 / 50$ & $51 / 49$ & 9.33 & 12.9 & g $68 \mathrm{~S}_{1} 85 \mathrm{~S}_{2} 188 \mathrm{I}$ & 4.7 \\
\hline CP-10 & 3d & 7d & $50 / 50$ & $55 / 45$ & 6.42 & 9.43 & g $68 \mathrm{~S}_{1} 89 \mathrm{~S}_{2} 184 \mathrm{I}$ & 7.7 \\
\hline
\end{tabular}

${ }^{a}$ Mole ratio of monomers in feed of the copolymerization.

${ }^{b}$ Composition of the copolymer, whose structure is shown in Scheme 4.

c Number- and weight-average molecular weights $\left(\bar{M}_{n}\right.$ and $\left.\bar{M}_{w}\right)$, determined by GPC measurement.

${ }^{d}$ The transition temperature was determined by DSC measurement on the heating scan, and the mesophase was determined by optical polarizing microscope and X-ray diffractometry. g, glassy state; $S, S_{1}$ and $S_{2}$, smectic phase; $N$, nematic phase; $I$, isotropic phase.

$e$ Enthalpy change at the isotropization temperature, determined by DSC measurement.

were dissolved in dry THF in a polymerization tube. The concentrations of the monomers and AIBN were $2.0 \mathrm{moll}^{-1}$ in total and 0.05 moll $1^{-1}$, respectively. The mole ratio of the monomers in each copolymerization is listed in Table 1. After degassing the mixture, the tube was sealed and heated at $60^{\circ} \mathrm{C}$ for $12 \mathrm{~h}$. The reaction mixture was then poured into excess methanol to precipitate the polymer. The obtained polymer was reprecipitated twice from its THF solution into excess methanol and dried in vacuo for $24 \mathrm{~h}$. The yields of the radical polymerizations were $60-70 \%$.

\section{Characterizations}

${ }^{1} \mathrm{H}$ NMR spectra of the copolymer to determine composition was conducted with a Bruker AM-400 FT-NMR (400 MHz) spectrometer using $\mathrm{CDCl}_{3}$ as the solvent. Gel permeation chromatography was carried out with a Tosoh HLC-802A instrument by using THF as eluent, equipped with four columns of TSK gels G5000H $\mathrm{H}_{6}, \mathrm{G} 4000 \mathrm{H}_{6}, \mathrm{G} 3000 \mathrm{H}_{6}$, and $\mathrm{G}^{2} 000 \mathrm{H}_{6}$. Standard polystyrenes were used for calibration.

Differential scanning calorimetry (DSC) was conducted with a Seiko Electronic DSC-20 with SSC-580 thermal controller at heating and cooling rates of $10^{\circ} \mathrm{Cmin}^{-1}$. A Nikon Microphot-UFX optical polarized microscope equipped with a Mettler FP-82 hot stage and Mettler FP-80 central processor was used to observe the thermal transition and analyze the anisotropic texture. X-ray diffraction patterns were recorded on a MAC Science MXP3 X-ray diffractometer, equipped with a thermal controller Model 5301.

\section{RESULTS AND DISCUSSION}

All monomers with a siloxane spacer, $7 \mathbf{a}-$ 7d, 12a, and 12b, were easily prepared from the corresponding mesogenic silanol compounds, 6a-6d, 11a and 11b. ${ }^{3}$ The spacer length of the monomers $\mathbf{3 a}-\mathbf{3 d}$ is almost equal to that of the monomers $7 \mathbf{a}-\mathbf{- 7 d}$, which is about $14 \AA$. However, it was found that, in the hydrosilylation of ethoxydimethylsilane with 
allyloxy compounds having the same laterally attached mesogens as $10 \mathbf{a}$ and $10 \mathbf{b}$, side reactions mainly occurred to afford the desired product in very low yields, whereupon the silyl group was eliminated in the major products. Therefore, butenyloxy compounds 10a and 10b were prepared instead of the corresponding allyloxy compounds like $\mathbf{5 a}-\mathbf{5 d}$, by which hydrosilylation could proceed successfully.

The copolymerizations of the monomer pairs

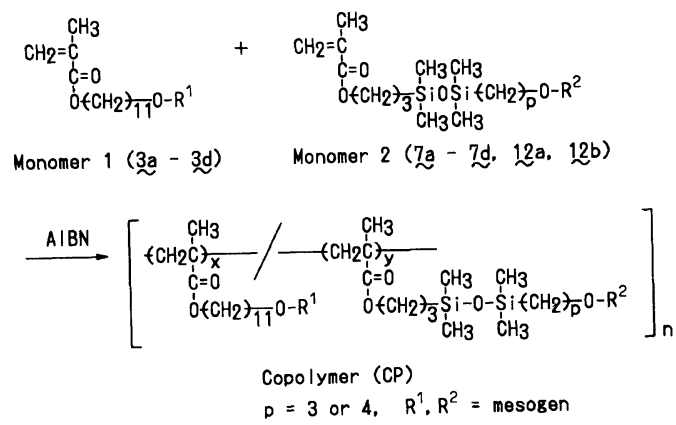

Scheme 4. Preparations of copolymers.

Table II. Results of preparations and thermal transitions of homopolymers

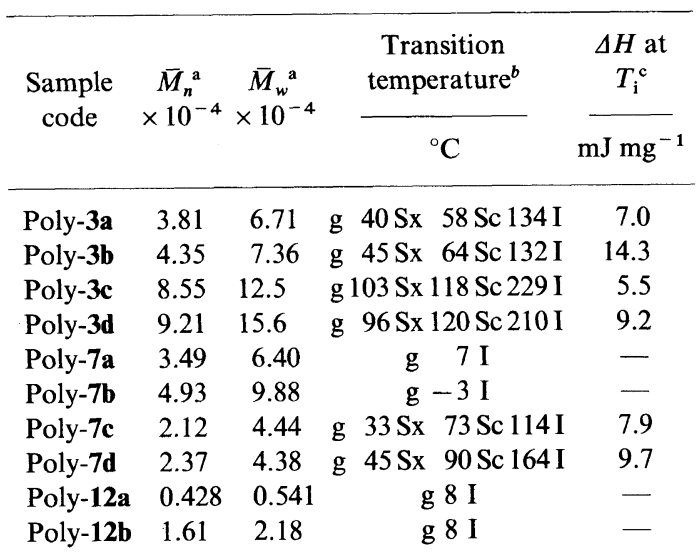

${ }^{a}$ Number- and weight-average molecular weights $\left(\bar{M}_{n}\right.$ and $\bar{M}_{w}$ ), determined by GPC measurement.

$b$ The transition temperature was determined by DSC measurement, and the mesogenic phase was determined by optical polarizing microscope and X-ray diffractometry. g, glassy state; Sx, unidentified smectic phase: Sc, smectic $\mathrm{C}$ phase; $\mathrm{I}$, isotropic phase.

c Enthalpy change at the isotropization temperature, determined by DSC measurement. were carried out by an ordinary radical polymerization with $2,2^{\prime}$-azobisisobutyronitrile (AIBN) as an initiator to afford random copolymers, as shown in Scheme 4. The copolymer composition $x / y$ was controlled by changing each monomer ratio in feed. The results of copolymerization and thermal properties of the copolymers are summarized in Table I, and Table II shows the characterizations of homopolymers obtained from the monomers by the same radical polymerization. The composition, $x / y$, of each copolymer was determined by the ratio of ${ }^{1} \mathrm{H}$ NMR peak intensities derived from the phenylene protons of mesogen and methylene protons next to the silyl group.

All copolymers obtained in this work showed an enantiotropic mesophase. The differential scanning calorimetry (DSC) curves of the copolymers on their first heating scan are shown in Figures 1 and 2, as compared with those of the homopolymers, poly-3a and poly-3b. On the cooling scan, the corresponding exothermic peaks were observed at the isotropization temperature $\left(T_{\mathrm{i}}\right)$ for all homopolymers and copolymers. As shown in these figures, the glass transition temperature $\left(T_{\mathrm{g}}\right)$ and $T_{\mathrm{i}}$ of the copolymers decreased with increasing content of the comonomer unit

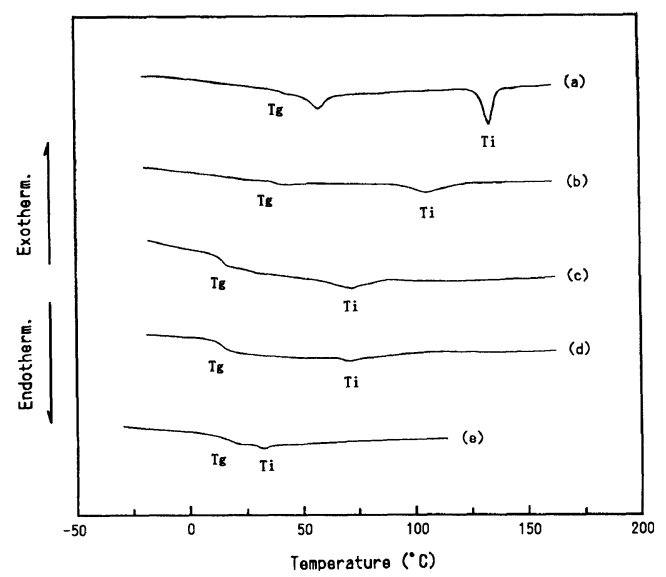

Figure 1. DSC curves displayed during the first heating scan (heating rate; $10^{\circ} \mathrm{C} \mathrm{min}^{-1}$ for (a) poly-3a, (b) CP-1, (c) CP-2, (d) CP-5, and (e) CP-6. 


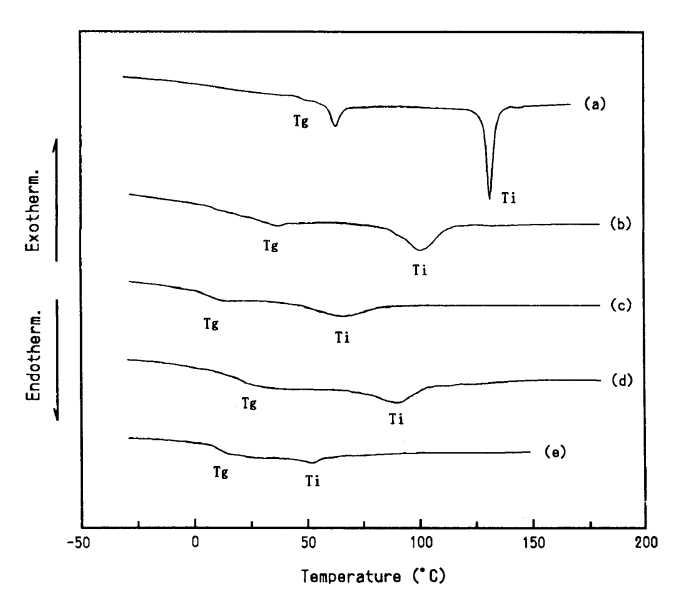

Figure 2. DSC curves displayed during the first heating scan (heating rate; $10^{\circ} \mathrm{C} \mathrm{min}^{-1}$ for (a) poly-3b, (b) CP-3, (c) CP-4, (d) CP-7, and (e) CP-8.

having a siloxane spacer. Therefore, it is suggested that $T_{\mathrm{g}}$ and $T_{\mathrm{i}}$ are affected by the chemical structure of the spacer component. In addition, the introduction of the comonomer containing a laterally attached mesogen was effective to lower the temperature range of the mesophase.

Figure 3 shows typical X-ray diffraction patterns of the homopolymer poly-3b and copolymers including the monomer unit of $\mathbf{3 b}$. Poly-3b indicated two peaks at low Bragg angle below $10^{\circ}$ (Figure 3, (a)-(c)), derived from the corresponding $d$-spacing of the smectic orientations of the mesogens. A sharp peak was observed in the higher angle region around $20^{\circ}$ for poly-3b at $25^{\circ} \mathrm{C}$ and $55^{\circ} \mathrm{C}$ (Figure 3, (a) and (b)). Therefore, poly-3b represents a highly ordered smectic phase in the low temperature range. The copolymer CP-3 and CP-7 also exhibited a smectic phase (Figures 3 , (d), (e), and (h)), whose comonomer content was about $25 \mathrm{~mol} \%$. On the other hand, in the case of the copolymers with a content of the $y$ component about $50 \mathrm{~mol} \%, \mathbf{C P}-\mathbf{4}$ and CP-8, no sharp peak in a lower nor higher Bragg angle region was observed, as shown in Figure 3, (f), (g), and (i). This is evidence that these copolymers exhibit only a nematic mesophase.

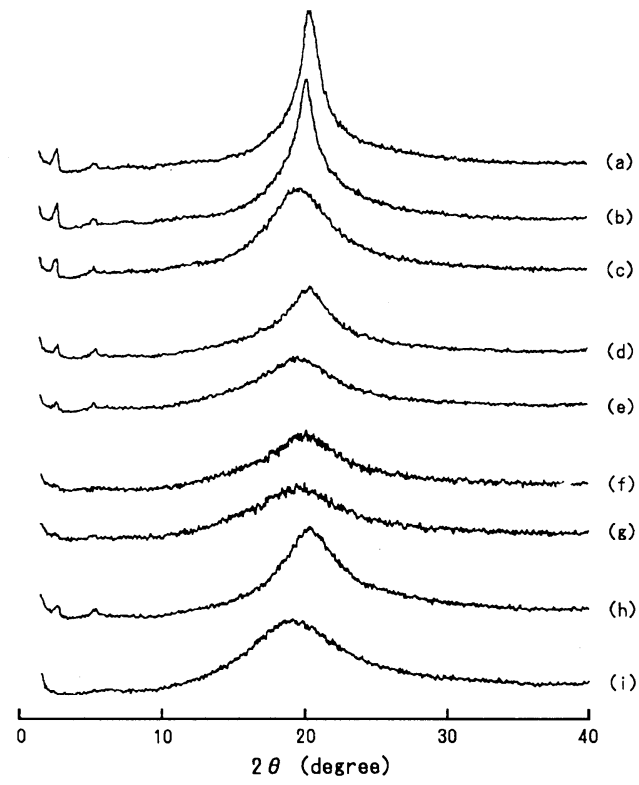

Figure 3. X-Ray diffraction patterns of the polymers at various temperatures measured by the powder method: (a) poly-3b at $25^{\circ} \mathrm{C}$, (b) poly-3b at $50^{\circ} \mathrm{C}$, (c) poly-3b at $100^{\circ} \mathrm{C}$, (d) CP-3 at $25^{\circ} \mathrm{C}$, (e) CP-3 at $90^{\circ} \mathrm{C}$, (f) $\mathrm{CP}-4$ at $25^{\circ} \mathrm{C}$, (g) $\mathrm{CP}-4$ at $55^{\circ} \mathrm{C}$, (h) CP-7 at $25^{\circ} \mathrm{C}$, and (i) CP-8 at $25^{\circ} \mathrm{C}$.

Figure 4 shows the representative optical polarizing micrographs of poly-3b, CP-3, CP-4, and CP-7 at about 10 degrees below $T_{\mathrm{i}}$. The homopolymer poly-3b represents the typical focal-conic texture of a smectic $\mathrm{C}$ mesophase. The value of $d$-spacing of the smectic layer calculated from X-ray diffraction peak supports the smectic $\mathrm{C}$ phase of poly-3b, which was $16.3 \AA$. The copolymer CP-3 showed a kind of bâtonnet texture growing very slowly, but the copolymers CP-4 and CP-7 showed such sanded textures. A similar tendency was observed in the results of X-ray diffraction and optical textures for homopolymer poly-3a and the copolymer series, CP-1, CP-2, CP-5, and CP-6, which contained a cyano end group. Thus, poly-3a, CP-1, and CP-5 exhibit a smectic phase, while CP-2 and CP-6, a nematic phase.

Our previous paper $^{3}$ reported that the copolymers whose spacers all included a disiloxane linkage with a triple-core mesogen 
Side-Chain LCP Containing Siloxane Spacer V.

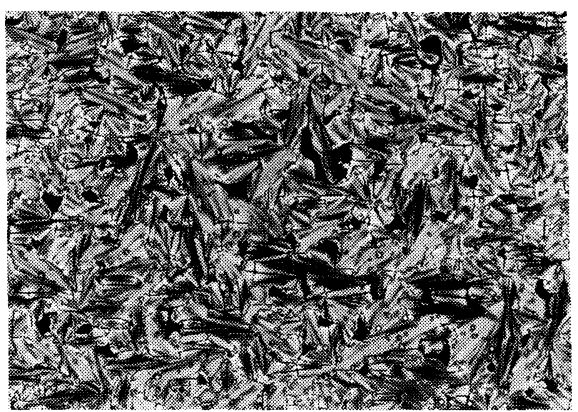

(a)

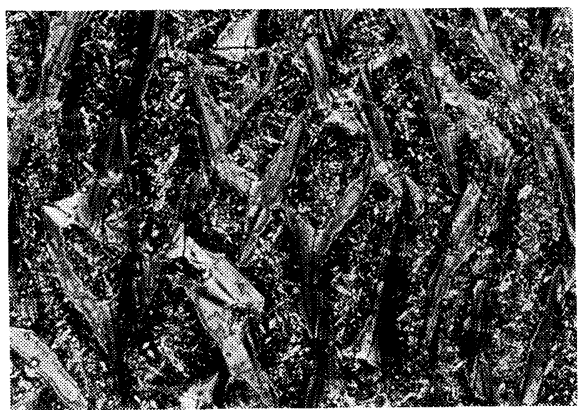

(b)

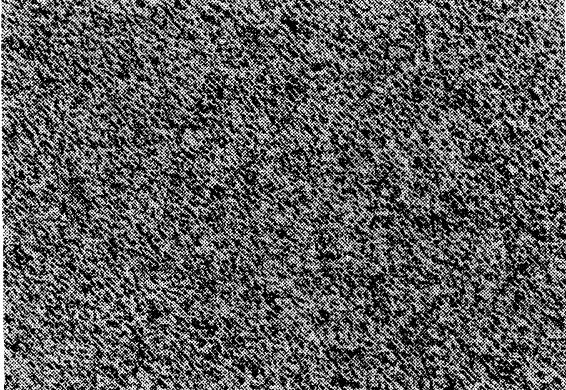

(c)

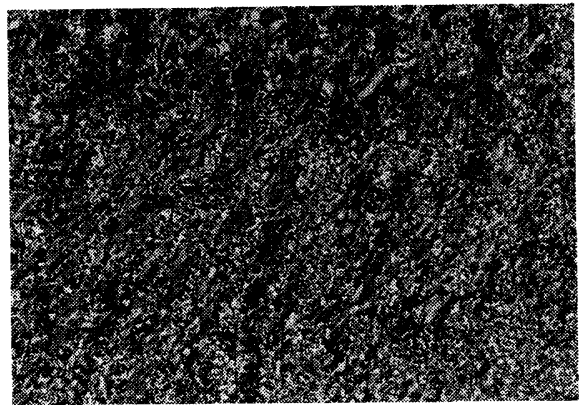

(d)

Figure 4. Typical optical polarizing micrographs of (a) poly-3b at $124.9^{\circ} \mathrm{C}$, (b) $\mathbf{C P}-3$ at $96.5^{\circ} \mathrm{C}$, (c) $\mathrm{CP}-4$ at $60.5^{\circ} \mathrm{C}$, and (d) CP-7 at $80.0^{\circ} \mathrm{C}$, maintained at this temperature for more than $1 \mathrm{~h}$ on cooling (magnification, $400 \times$ ).

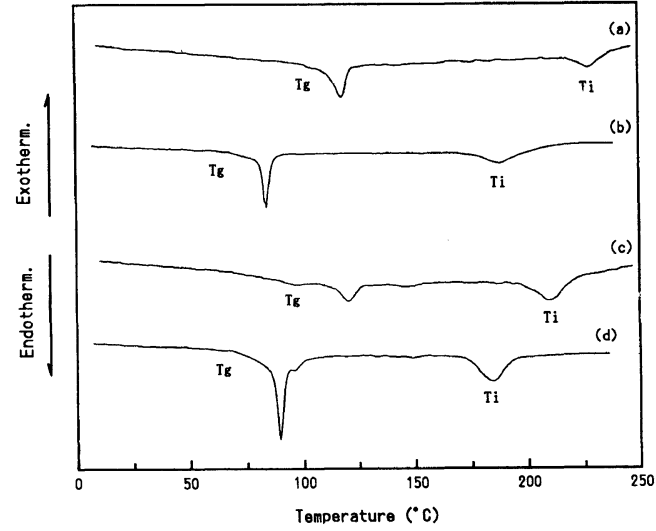

Figure 5. DSC curves displayed during the first heating scan (heating rate; $10^{\circ} \mathrm{Cmin}^{-1}$ for (a) poly-3c, (b) CP-9, (c) poly-3d, and (d) CP-10.

and a double-core or a laterally attached mesogen exhibited only a nematic phase, even with the introduction of $9 \mathrm{~mol} \%$ comonomer unit. In the case of the copolymers, smectic orientation might be hindered by the bulky

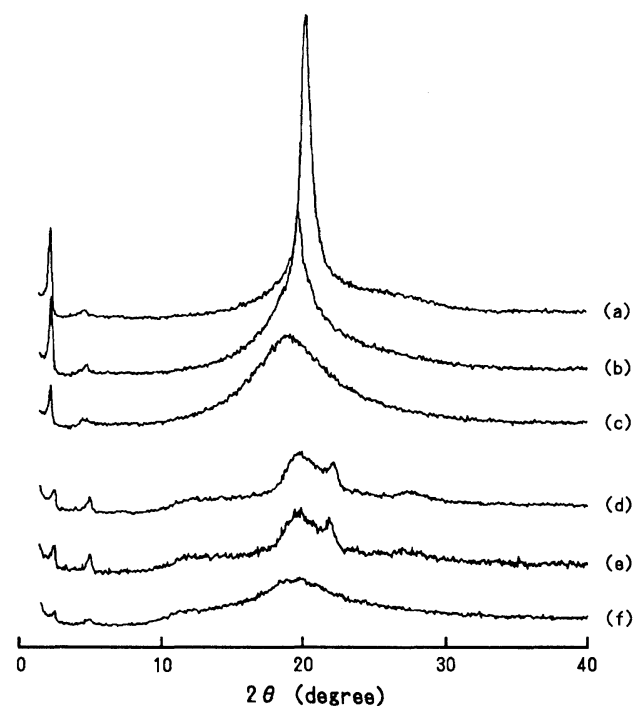

Figure 6. X-Ray diffraction patterns of the polymers at various temperatures measured by the powder method: (a) poly-3c at $25^{\circ} \mathrm{C}$, (b) poly-3c at $115^{\circ} \mathrm{C}$, (c) poly-3c at $190^{\circ} \mathrm{C}$, (d) CP-9 at $25^{\circ} \mathrm{C}$, (e) CP-9 at $65^{\circ} \mathrm{C}$, and (f) CP-9 at $160^{\circ} \mathrm{C}$. 


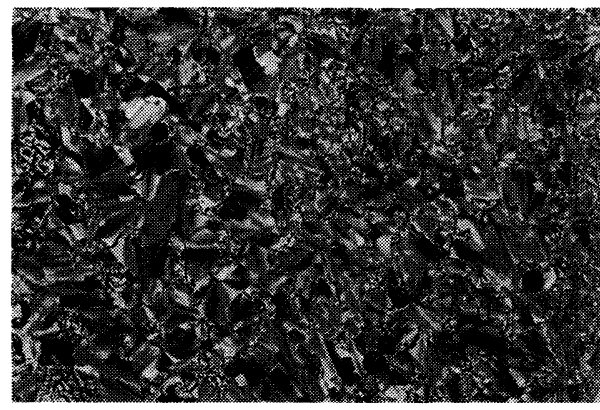

(a)

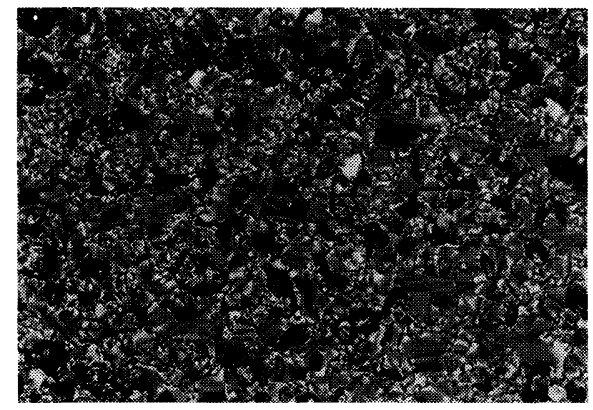

(b)

Figure 7. Typical optical polarizing micrographs of (a) CP-9 at $170.1^{\circ} \mathrm{C}$ and (b) $\mathrm{CP}-10$ at $165.2^{\circ} \mathrm{C}$, maintained at this temperature for more than $1 \mathrm{~h}$ on cooling (magnification, $400 \times$ ).

spacer component. On the other hand, in the case of copolymers whose spacers consisted of two components of an alkylene and a siloxane spacer, the smectic layer was not destroyed when comonomer content was less than about $30 \mathrm{~mol} \%$, as described above. Probably, the alkylene spacer component makes it easier to establish a smectic layer of mesogens.

The copolymers CP-9 and CP-10 which contain triple-core mesogens with a content of the $y$ component nearly $50 \mathrm{~mol} \%$ were prepared as shown in Table $\mathrm{I}$, in order to compare their thermal properties with CP1-CP-8. Figure 5 shows DSC curves of these copolymers compared with the parent homopolymers, poly-3c and poly-3d. Similar transitions were observed for CP-9 and CP-10 as those of poly-3c and poly-3d, respectively, where they exhibited two kinds of mesophases between $T_{\mathrm{g}}$ and $T_{\mathrm{i}}$. The sharp peaks were observed at $85^{\circ} \mathrm{C}$ for CP-9 and at $89^{\circ} \mathrm{C}$ for CP-10 on a heating scan of DSC trace (Figure 5), and on a cooling scan, corresponding exothermic peaks were observed. However, $T_{\mathrm{g}}$ and $T_{\mathrm{i}}$ of the copolymers were lower than those of the homopolymers. Figure 6 shows typical X-ray diffraction patterns of poly-3c and CP-9. Poly-3c indicated the two peaks at low Bragg angle below $10^{\circ}$, which were derived from the corresponding $d$-spacing of the smectic orientations of the mesogens. In addition, for poly-3c, sharp peaks were observed in the higher angle region around $20^{\circ}$ at $25^{\circ} \mathrm{C}$ and $115^{\circ} \mathrm{C}$ (Figures 6, (a) and (b)). Therefore, poly-3c represents a highly ordered smectic phase in the low temperature range. A similar tendency was observed for copolymer CP-9. Thus, the copolymers containing a triple-core mesogen exhibit a smectic phase including a highly ordered one at lower temperature region, because the large mesogenic group easily brought about smectic orientation even in such a copolymer system. Figure 7 shows optical micrographs of CP-9 and CP-10. These copolymers showed a broken fan texture of the smectic mesophase, and this texture was also observed at room temperature.

Consequently, in the copolymer system containing siloxane spacer, the mesophase and temperature range of liquid-crystalline state could be controlled by the introduction of comonomer units. The flexible siloxane spacer very effectively lowers the temperature range of the mesophase of side-chain LCPs.

\section{REFERENCES}

1. H. Finkelmann, H. Ringsdorf, and J. H. Wendorff, Makromol. Chem., 179, 273 (1978).

2. Y. Nagase and Y. Takamura, Makromol. Chem., 193, 1225 (1992).

3. Y. Nagase, Y. Takamura, H. Abe, K. Ono, T. Saito, and E. Akiyama, Makromol. Chem., 194, 2517 (1993).

4. Y. Nagase, T. Saito, H. Abe, and Y. Takamura, 
Side-Chain LCP Containing Siloxane Spacer V.

Macromol. Chem. Phys., 195, 263 (1994).

5. E. Akiyama, M. Yamazaki, Y. Takamura, and Y. Nagase, Macromol. Chem., Rapid Commun., 15, 161 (1994).

6. M. Engel, B. Hisgen, R. Keller, W. Kreuder, B. Reck, H. Ringsdorf, H. Schmidt, and P. Tschirner, Pure Appl. Chem., 57, 1009 (1985).
7. Y. Kawakami, K. Toida, and Y. Ito, Macromolecules, 26, 1177 (1993).

8. For example, V. Percec and M. Lee, Macromolecules, 24, 4963 (1991).

9. Y. Kanaoka, K. Tanizawa, E. Sato, O. Yonemitsu, and Y. Ban, Chem. Pharm. Bull., 15, 593 (1967). 